\title{
Tecnologias e Saúde Mental: uma Plataforma de Jogos Digitais para Jovens com Transtorno de Desenvolvimento
}

\section{Technology and Mental Health: a Digital Game Platform for Young People with Developmental Disorders}

FRANCISCO MILTON MENDES NETO Universidade Federal Rural do Semi-Árido

KARLA ROSANE DO AMARAL DEMOLY Universidade Federal Rural do Semi-Árido

EVERTON J ALES DE OLIVEIRA Universidade Federal Rural do Semi-Árido

MARIZA SOUZA MOURA Universidade Federal Rural do Semi-Árido

RAFAEL DE ALMEIDA RODRIGUES Universidade Federal Rural do Semi-Árido

RAMIRO DE VASCONCELOS DOS SANTOS JUNIOR

Universidade Federal Rural do Semi-Árido

\begin{abstract}
Resumo: Esta pesquisa apresenta o percurso de implementação de uma plataforma de jogos digitais junto a oficinas que fazemos com jovens atendidos no CAPSi - Centro de Atenção Psicossocial da Infância e da Adolescência de Mossoró. O aporte teórico que sustenta o trabalho considera os estudos de Gilbert Simondon sobre os processos de individuação dos seres vivo, físico e técnico e as construções de Francisco Varela sobre o modo de funcionamento da cognição. A metodologia empregada é qualitativa integrando a tessitura de diários de bordo nas oficinas, a análise de dispositivos presentes em jogos e a escolha de tecnologias para a construção da plataforma. Utilizamos como ferramenta de desenvolvimento a Unity. Como resultados do trabalho, indicamos as mudanças cognitivas e afetivas que pudemos distinguir como recorrentes no percurso dos jovens autistas nas oficinas de jogos e o estágio de desenvolvimento da plataforma que será validada em ambientes de saúde mental e educação.
\end{abstract}

Palavras-chave: Plataforma de jogos. Jovens. Autismo. Cognição. Saúde mental.

\begin{abstract}
This paper presents the accomplishment process of a digital gaming platform through workshops developed among youth in psychic suffering, treated at CAPSi - Psychosocial Care Center for Children and Adolescents in Mossoró. The theoretical framework that supports this work especially considers Gilbert Simondon studies on the individuation process of living beings in a physical and technical intersection and the production of Francisco Varela on cognition function. The implemented methodology is qualitative integrating the interweave of logbooks during workshops, games devices overview and the choice of appropriate technologies for the development of the digital gaming platform. As results of this research, we present cognitive and affective transformations that we could distinguish as recurrent on autistic youth during the gaming workshops and the final stage of the platform completion, which will be validated in mental health and education environments.
\end{abstract}

Keywords: Gamming Platform. Young. Autism. Cognition. Mental health.

MENDES NETO, Francisco Milton; DEMOLY, Karla Rosane do Amaral; OLIVEIRA, Everton Jales; MOURA, Mariza Souza; RODRIGUES, Rafael de Almeida; SANTOS JUNIOR, Ramiro Vasconcelos. Tecnologias e Saúde Mental: uma plataforma de jogos digitais para jovens com transtorno de desenvolvimento. Informática na Educação: teoria \& prática, Porto Alegre, v.20, n. 2, p. 258-271, mai./ago. 2017. 


\section{I ntrodução}

Neste artigo discutimos a implementação de uma plataforma de jogos digitais para favorecer a experiência de jovens com transtorno de desenvolvimento que são atendidos em um Centro de Atenção Psicossocial de Mossoró. O quadro teórico que subsidia nossa análise é composto pelos conceitos de individuação dos seres vivo, físico e técnico, desenvolvido por Gilbert Simondon (1958, 1989; 2009) e pelo conceito de enação construído por Francisco Varela e seus colaboradores Evan T. Thompson e Eleanor Rosch (2001). O trabalho destes cientistas favorece nosso entendimento sobre as circunstâncias do viver humano na relação com as tecnologias e, no caso de nossa pesquisa, a experiência de jovens com transtorno de desenvolvimento - autismo, deficiências mentais, depressão - em oficinas de jogos digitais. A metodologia que utilizamos neste percurso de invenção de uma plataforma digital de jogos envolve a pesquisa intervenção, com o emprego de oficinas semanais de jogos digitais propostas por estudantes e pesquisadores do Programa Rede de Oficinandos na Saúde ${ }^{1}$ em um ambiente de saúde mental. A plataforma está sendo desenvolvida em jogos multiplataforma utilizando a Unity ${ }^{2}$. A escolha se deu pela compatibilidade com outras tecnologias e aceitação em diversos dispositivos.

Nesta escrita apresentamos o percurso de construção e conceitos que operam na arquitetura e dispositivos da plataforma. Estamos propondo artefatos modelados a partir de oficinas semanais em um ambiente de saúde mental, oficinas de jogos que favorecem a observação e análise de modos de coordenar condutas: gestos, ideias e emoções na experiência.

Escritas em diários de bordo de estudantes e pesquisadores durantes as oficinas no CAPSi permitem aceder ao "en-atuar" dos jovens e aos dispositivos presentes nos jogos que fazem disparar processos cognitivos, como modos de interagir, formas de funcionamento da atenção e de exercício de autoria. As oficinas na pesquisa intervenção são concebidas como tecnologias sociais que permitem observar e distinguir pistas, o percurso dos jovens e as características que se destacam nos jogos, compondo informações essenciais que levamos em conta na implementação da plataforma.

Iniciaremos com a explicitação de como conceitos centrais do trabalho - individuação psíquica e coletiva e en-ação operam na experiência em que jogamos e aprendemos com os jovens no CAPSi de Mossoró/RN, um fazer que acontece semanalmente, desde janeiro do ano de 2012. Em seguida trazemos dois recortes: as ações dos jovens no jogar e as características dos jogos já instalados no ambiente do Programa Rede de Oficinandos na Saúde. Os diários de bordo permitiram observar o en-agir dos jovens, contando com os dispositivos presentes nos jogos - sons, imagens, vídeos, animação, tempo, cenário ou design, personagens,

\footnotetext{
${ }^{1}$ O programa Rede Oficinandos na Saúde é uma experiência que reúne projetos de extensão através de uma parceria entre a Universidade Federal Rural do Semi-Árido e o Centro de Atenção Psicossocial da Infância e da Adolescência (CAPSi). O programa utiliza tecnologias da informação e comunicação com o propósito de produzir modos de inserção social, cuidado e formação em saúde mental. A experiência conta com o apoio e colaboração de pesquisadores das universidades UFRGS, UFC, UNISC e UFAL e, desde o ano de 2011 é financiada pelo Ministério da Educação - PROEXT/MEC/SESU.

2Informações sobre a Unity estão disponíveis no endereço: https://unity3d.com/pt/unity.
} 
interatividade, inatividade. Estes dispositivos favorecem a observação de circunstâncias em que manifestam medo, sofrimento, por exemplo, quando um jovem tampa os ouvidos e fecha os olhos diante de luzes e sons. Estas são apenas algumas das pistas que, na experiência direta com os jovens, levamos em consideração na proposta da implementação de uma plataforma de jogos digitais.

Para finalizar o texto, apresentaremos as definições para a plataforma e a atualidade de sua implementação, trabalho este que é realizado por uma equipe transdisciplinar que integra pesquisadores e estudantes das ciências humanas e da ciência da computação. Ao final desta construção, apresentaremos alguns resultados importantes que decorrem da experiência de interação de jovens com transtorno de desenvolvimento em oficinas de jogos digitais.

\section{As experiências humana e técnica}

Ao interagir em oficinas, inicialmente nós nos colocamos a seguinte questão: - Como jovens deslocam e/ou transformam processos cognitivos e afetivos na experiência e interação com jogos digitais? A pergunta desencadeou a reflexão sobre como acontece a experiência humana nas dimensões cognitiva, técnica e social e recorremos aos estudos de Gilbert Simondon e Francisco Varela.

\subsection{Gilbert Simondon e a individuação humana, física e técnica}

Simondon é considerado o filósofo da técnica por ter se dedicado a estudos sobre os processos de individuação psíquica e coletiva e sobre a individuação dos objetos técnicos, esclarecendo sobre a estreita relação entre a configuração dos objetos técnicos e as diferentes sociedades que vamos construindo.

A operação de individuação descrita na obra do autor é importante no trabalho de implementação de uma plataforma de jogos, pois permite distinguir um modo de olhar e explicar os encontros que acontecem entre os jovens e os artefatos técnicos nas oficinas.

Equipamos um ambiente de saúde mental do município de Mossoró no ano de 2012 onde temos oito computadores conectados à Internet, oito tablets, oito câmeras fotográficas, papeis, tintas, lápis de cor, tesouras, entre outros artefatos que favorecem o linguajar. Para Maturana, tudo o que nós os humanos fazemos ocorre enquanto rede de conversações e estas se tecem no contínuo entrelaçamento de linguagens e emoções. As ações na linguagem o autor distingue como "linguajar" e jogar é um modo de linguajar.

Interagimos nas oficinas no CAPSi com grupos de oito jovens, nas quintas e sextas feiras, perfazendo um coletivo de cerca de sessenta e quatro jovens. Os diagnósticos feitos pela equipe interdisciplinar que os atende na instituição indicam circunstâncias, como: autismo, deficiência mental e/ou depressão. Precisávamos construir um caminho para compreender as ações, os sofrimentos, as alegrias, saberes dos jovens que observávamos no percurso das oficinas. 
Em sua tese, Simondon oferece algumas pistas para compreender o modo de existência dos seres humanos em seus processos de individuação psíquica e coletiva. Ao problematizar a gênese do indivíduo, o autor esclarece de que é preciso deslocar-se da noção de "forma" para a de "informação", quando queremos compreender processos de individuação. Assim, o indivíduo físico, vivo ou técnico experimenta atualizações nos processos de individuação que acontecem no percurso de existência dos mesmos.

Ao analisar a história da Filosofia Ocidental, Simondon (2009) pensa a problemática do sujeito na análise que faz dos sistemas metaestáveis, que são irredutíveis à ordem da identidade. O indivíduo, nesta perspectiva, é resultante da operação de individuação, seja na dimensão dos seres vivos físicos ou técnicos. De acordo com o autor:

\begin{abstract}
Existem duas vias segundo as quais a realidade do ser como indivíduo pode ser abordada: uma via substancialista, considerando o ser como consistindo em sua unidade, dado a si mesmo, fundado sobre si mesmo, engendrado, resistindo àquilo que não é ele mesmo; uma via hilemórfica considerando o indivíduo como engendrado pelo encontro de uma forma e de uma matéria (SIMONDON, 2009, p.23).
\end{abstract}

Simondon questiona a ambas as vias, pois acabam definindo o propósito de busca por um "princípio de individuação" que as sustenta no sentido de que este princípio explica uma realidade encontrada. (SIMONDON, 2009, p.26). As visões substancialista e /ou hilemórfica, tomadas como explicação para o modo de existir dos seres humanos, consideram como ponto de partida "o indivíduo constituído e dado", em um esforço "para remontar às condições de sua existência" (SIMONDON, 2009, p.23). O autor sustenta a perspectiva da ontogênese que focaliza as fases do ser, designando seu caráter de devir, o qual precede à tomada de forma, visibilizando os regimes pelos quais o sujeito passa a existir.

Assim, no contexto do nosso trabalho, os jovens em circunstância de transtorno de desenvolvimento, assim como cada um de nós com nossas potências e fragilidades, surgem em decorrência de um sistema em tensão metaestável (energia potencial), sempre em devir. Ao contrário de processos estáveis, da afirmação de identidades cristalizadas em um modo de ser que definiria como somos e porque assim o somos, o que se passa é uma "[...] comunicação permanente, mantendo uma metaestabilidade que é condição de vida" (SIMONDON, 2009, p. 25)

Enquanto examinarmos apenas os limites da aparência (forma e conteúdo), o que nos ambientes de saúde mental e de educação aparecem na forma de escritas - diagnósticos, registros sobre estudantes -, estaremos reforçando uma perspectiva que cristaliza uma posição para o sujeito - jovem com transtorno de desenvolvimento -, enfatizando as fragilidades no lugar das potências do vir a ser, tornar-se no transcurso da experiência, o que implica devir humano.

[...] o devir não é uma moldura na qual o ser existe; ele é dimensão do ser, modo de resolução de uma incompatibilidade inicial rica em potenciais. A individuação corresponde ao surgimento de fases no ser que são as fases do ser; ela não é uma consequência depositada no limiar do devir e isolada, mas esta própria operação se realizando. 
O propósito de nosso trabalho é construir uma plataforma de jogos digitais contando com a observação e análise de mudanças cognitivas e afetivas na experiência de oficinas com jovens em circunstâncias de transtornos mentais. Levamos em conta a energia potencial dos processos de individuação nos quais nos fazemos humanos.

Sobre o modo como compreendemos as circunstâncias de jovens com transtornos de desenvolvimento, tornamos visíveis em diários de bordo construídos nas oficinas as potencialidades dos jovens em situações de jogo, pois nossa atenção está deslocada para as operações de individuação que experimentam ao se defrontarem com problemas e produzirem soluções/atualizações. As oficinas de jogos digitais acontecem em grupos, o que se apresenta como uma novidade no CAPSi onde os atendimentos são preponderantemente individuais. Sobre a dimensão subjetiva que integra a vida humana, Simondon chama nossa atenção para o coletivo:

\begin{abstract}
O psiquismo e o coletivo são constituídos por individuações que sucedem a individuação vital. O psiquismo é a perseguição da individuação vital em um ser que, para resolver sua própria problemática, é obrigado a intervir ele mesmo como elemento do problema, por sua ação, como sujeito; o sujeito pode ser concebido como a unidade do ser enquanto ser vivo individuado e enquanto ser que representa sua ação para si mesmo através do mundo como elemento e dimensão do mundo; os problemas vitais não são fechados sobre si mesmos; sua axiomática aberta só pode ser saturada por uma sequência indefinida de individuações sucessivas que empregam sempre mais realidade préindividual e a incorporam na relação ao meio; afetividade e percepção se integram em emoção e em ciência que supõem um recurso a dimensões novas (SIMONDON, 2009, p. 30).
\end{abstract}

Como recurso a dimensões novas, o autor discute a potência da ação sobre si mesmo e no coletivo, o que ajuda a pensar sobre a tecnologia social que empregamos na pesquisa intervenção - as oficinas - em que os jovens são convidados a uma experiência de jogar com o outro, interagir. Simondon segue sua reflexão sobre a ação sobre si mesmo, a busca de resolução de problemáticas vitais nesta dimensão psíquica e também coletiva.

\begin{abstract}
Entretanto o ser psíquico não pode resolver em si mesmo sua própria problemática; sua carga de realidade pré-individual; ao mesmo tempo em que se individua como ser psíquico que ultrapassa os limites do ser vivo individuado e o incorpora em um sistema do mundo e do sujeito, permite a participação sob forma de condição de individuação do coletivo; a individuação sob forma de coletivo faz do indivíduo um indivíduo de grupo, associado ao grupo pela realidade pré-individual que ele traz em si e que, reunida à dos outros indivíduos, se individua em unidade coletiva. As duas individuações, psíquica e coletiva, são recíprocas uma com relação à outra; elas permitem a definição de uma categoria do transindividual que tende a dar conta da unidade sistemática da individuação interior (psíquica) e da individuação exterior (coletiva) (SIMONDON, 2009, p. 30)
\end{abstract}

Neste ponto, é por intermédio de um corpo que experimenta processos de individuação que a informação se atualiza. Assim, o corpo passa a ser compreendido como plano de inscrição da experiência no encontro dos jovens com jogos digitais. Passamos a compreender que a individuação não envolve captação de uma realidade, mas sim deslocamentos e atualizações que emergem como efeito do encontro de um corpo com um sinal perceptivo (visual, sonoro, 
olfativo, sensorial, gustativo ou abstrato), o qual possibilita o ser vivo individuado interagir com o mundo em uma relação de coprodução.

No contexto desta pesquisa, compreender o campo problemático que se instaura com o desafio do desenvolvimento de uma plataforma de jogos digitais para a saúde mental requer a explicitação dos nossos entendimentos sobre como o dispositivo jogo pode favorecer a experiência de jovens com transtorno de desenvolvimento. E, neste ponto, é importante distinguir que os seres humanos se individuam mediante uma ação encarnada, corpórea, tal como indica Francisco Varela (2003), outro pesquisador com o qual interagirmos na construção de nossa pesquisa.

\title{
2.2 Francisco Varela e a Enação
}

Podemos afirmar, inspirados em Varela, Thompson e Rosch (2001) que o ser humano configura o conhecimento e as realidades em que vive em processos que conceituam como enação, fazendo a cognição diferenciar-se permanentemente de si mesma.

\begin{abstract}
[...] a cognição não é a representação de um mundo preestabelecido elaborada por uma mente pré-definida, mas é antes a atuação de um mundo e de uma mente com base numa história da variedade das ações que um ser executa no mundo (p. 32).

[...] primeiro, que a cognição depende dos tipos de experiência que surgem do fato de se ter um corpo com várias capacidades sensório-motoras e, segundo, que estas capacidades sensório-motoras individuais se encontram elas próprias mergulhadas num contexto biológico, psicológico e cultural muito mais abrangente (VARELA, THOMPSON e ROSCH, 2001, p. 226).
\end{abstract}

Ao indicarem o que implica os processos em que nos tornamos humanos e seguimos atualizando modos de conhecer, viver, sentir, fazer nos movimentos da cognição, podemos aproximar os estudos dos autores da perspectiva de Simondon, pois em ambas as teorias temos que os indivíduos humanos se transformam em congruência, nos processos que articulam potências, energias, modos de agir na linguagem, tornando visíveis emoções como alegria e/ou dor nos percursos de vida e conhecimento.

A criação de novos mundos implica uma diferenciação de si próprio e uma transformação estrutural, de acordo com a própria definição de "mente corporificada".

[...] a cognição depende dos tipos de experiência que surgem do fato de se ter um corpo com várias capacidades sensório-motoras e, segundo, [...] estas capacidades sensório-motoras individuais se encontram elas próprias mergulhadas num contexto biológico, psicológico e cultural muito mais abrangente (VARELA; THOMPSON; ROSCH, 2001, p. 226).

Ao analisarmos como os jovens coordenam suas ações no ambiente equipado com jogos já disponíveis, percebemos que atualizam modos de sentir, fazer, interagir nas oficinas e vamos definindo pistas para produzir uma plataforma de jogos pertinentes aos seus percursos de vida e conhecimento. Temos, ao mesmo tempo, o trabalho de observar e distinguir modos perceptivos sensórios motores, isto é, como jogam, onde pousam a atenção, que jogos mais os atraem (considerando aqui aqueles jogos já disponíveis no ambiente das oficinas). Outro 
trabalho necessário foi distinguir características presentes nos jogos e os efeitos que estes dispositivos produzem na experiência dos jovens: agradam, assustam, alegram, entristecem. Diferentes mídias, como sons, imagens, personagens, cenários, escritas, enfim, estes elementos e as operações, desafios que os jogos colocam aos jogadores, precisariam integrar a plataforma de modo a expandir as potencialidades dos jovens no transcurso da experiência.

\section{Oficinando com jovens e jogos digitais em um ambiente de saúde mental}

Organizamos oficinas em um ambiente equipado com diferentes tecnologias que favorecem a interação, como jogos de computador e tablets. O ambiente onde nossa pesquisa se desenvolve é o CAPSi que atende em média cento e cinquenta jovens com transtornos mentais de Mossoró e vindos de cidades circunvizinhas.

O programa Rede de Oficinandos na Saúde intensificou a experiência com a tecnologia jogos digitais a partir de janeiro de 2013, quando bolsistas de extensão e de pesquisa passaram a organizar oficinas de jogos no CAPSi. Temos atualmente participando das oficinas jovens com autismo, depressão e/ou deficiência mental e acompanhamos a experiência compondo diários de bordo. O Programa envolve sessenta e quatro jovens nas oficinas, divididos em pequenos grupos de oito, durante uma hora, em dois momentos nas quintas-feiras e sextas-feiras, turnos da manhã e da tarde.

Para esta escrita consideramos as escritas dos diários de bordo referidas a oito jovens que estudam nos anos iniciais do ensino fundamental e, ao mesmo tempo, participam de terapias e das oficinas do Programa Rede de Oficinandos na Saúde.

Os jogos instalados em computadores e tablets inicialmente estão disponíveis na internet. Crawford (1982) esclarece que temos diferentes tipos de jogos e, baseados nos estudos de Monte (2014) descrevemos na Tabela 1 características dos jogos utilizados nas oficinas.

Tabela 1. Descrição de tipos de Jogos

\begin{tabular}{|c|l|}
\hline Tipo de Jogo & \multicolumn{1}{|c|}{ Descrição da forma de jogo e exemplo } \\
\hline Jogos de ação & $\begin{array}{l}\text { Enfatizam a reação instantânea e precisam de intensa concentração do } \\
\text { jogador: Mario Word }{ }^{3}, \text { Chicken Invaders }^{4} \text {. }\end{array}$ \\
\hline Jogos de Simulação & $\begin{array}{l}\text { Procuram reproduzir com fidelidade um fenômeno ou acontecimento, } \\
\text { buscando aproximações com aspectos da realidade vivida em um } \\
\text { contexto/cenário: rally de carros }{ }^{5} \text {, passeio e resgate de helicóptero }\end{array}$ \\
\hline Jogos de Aventura & $\begin{array}{l}\text { Procuram fazer o jogador pensar para seguir no jogo, muitas vezes contam } \\
\text { com a solução de um problema ao longo da ação: Subway Surfers }\end{array}$ \\
\hline
\end{tabular}

3 Mario World disponível em <http://nintendo.wikia.com/wiki/Super Mario World>.

4Chicken Invaders disponível em <https://www.interactionstudios.com/chickeninvaders.php>.

5 Rush Rally disponível em <https://play.google.com/store/apps/details?id=brownmonster.app.game. rushrally\&hl=pt-br> 6 Gunship Battle disponível em <https://play.google.com/store/apps/details?id=com.theonegames.gunshipbattle\&hl=ptbr>

7 Subway Surfers disponível em <https://play.google.com/store/apps/details?id=com.kiloo.subwaysurf> 


\begin{tabular}{|c|l|}
\hline $\begin{array}{c}\text { Jogos de Interpretação de } \\
\text { Personagens }\end{array}$ & $\begin{array}{l}\text { O jogador deve interpretar um personagem que pode ser da vida real. Uma } \\
\text { possibilidade deste jogo é ajudar o jogador a resolver questões do } \\
\text { personagem, a interagir, brincar e fazer falar os personagens, por } \\
\text { exemplo, os gatinhos no Tablet }{ }^{8} \text {. }\end{array}$ \\
\hline Jogos de estratégia & $\begin{array}{l}\text { Requerem que o jogador gerencie um conjunto limitado de recursos para } \\
\text { atingir um objetivo predefinido. Geralmente, gerenciar estes recursos } \\
\text { envolve decidir que unidade criar e onde colocá-la em ação. Outros jogos } \\
\text { de estratégia são baseados em turnos, onde o jogador utiliza o tempo para } \\
\text { tomar as decisões e o computador age quando o jogador indicar que está } \\
\text { pronto. Mário Word, Chickens, Resgate de helicóptero. }\end{array}$ \\
\hline
\end{tabular}

Fonte: elaborada pelos autores.

Apresentaremos a seguir recortes do percurso de alguns jovens que chamaremos por nomes fictícios, preservando suas identidades. Indicaremos características que os jogos precisam considerar quando propostos para um trabalho na saúde mental. Os recortes foram produzidos a partir de escritas de diários de bordo que são tecidos a cada encontro/oficina onde interagimos e jogamos juntos, oferecendo no ambiente uma diversidade de jogos digitais.

\subsection{Coordenações de condutas na experiência de jovens com jogos digitais}

As ações no jogo provocam mudanças nas coordenações de ações, coordenações de sentido, coordenações de gestos, coordenações de emoções. Levamos em conta estas operações cognitivas na experiência dos jovens e refletimos sobre as circunstâncias de suas vidas, no caso do presente texto, as circunstâncias do autismo, da deficiência mental e da depressão.

É sempre delicado pensar em características que remetem a todos, pois a perspectiva com a qual trabalhamos aponta para as singularidades, as circunstâncias de cada jovem, sujeito de sua vida e história. Cada sujeito é único em seu modo de viver-conhecer-sentir, portanto nas oficinas buscamos este olhar atento em que aprendemos com cada jovem sobre como interage com os jogos. Jamais será do mesmo modo que se apresentam as circunstâncias do autismo, da deficiência mental e/ou da depressão. Então, em meio a este alerta, apontamos alguns elementos que nos parecem necessários de considerar no trabalho de desenvolvimento de uma plataforma de recomendação de jogos digitais, um quadro que tecemos com base na experiência direta e imediata com os sujeitos nas oficinas.

Jogar implica produzir modos interagir nas oficinas, trabalho este importante na promoção da saúde mental. Observamos e distinguimos mudanças afetivas e cognitivas como modos de coordenar condutas nas oficinas de jogos.

Novas coordenações de ações em oficinas de jogos digitais produzem deslocamentos nos modos de composição das experiências sensoriais, estéticas, afetivas e cognitivas. Os jovens que participaram dessa observação estão em circunstâncias como o autismo, a deficiência mental e/ou a depressão, como já indicamos, mas nesse artigo serão apresentadas apenas

8 Talking Tom disponível em <https://play.google.com/store/apps/details?id=com.outfit7.talkingtom> 
nossas construções referidas às circunstâncias de jovens com autismo, devido à necessidade de um recorte para composição da escrita.

A Tabela 2 apresenta ações recorrentes que nos permitem distinguir mudanças nas coordenações de ações na experiência: coordenações de gestos, coordenações de ideias, coordenações de emoções. As oficinas de jogos favorecem a observação e análise de mudanças afetivas e cognitivas, os movimentos da cognição inventiva em que mundo e sujeitos se constroem mutuamente. Aqui recortamos nesta escrita a análise de nossa experiência com jovens autistas.

Tabela 2. Tabela contendo modos de coordenar condutas recorrentes na experiência, dispositivos presentes nos jogos já conhecidos e dispositivos a estarem presentes na plataforma.

\begin{tabular}{|c|c|c|}
\hline $\begin{array}{l}\text { Coordenações } \\
\text { oficinas }\end{array}$ & de Ações iniciais na experiência das & $\begin{array}{l}\text { Dispositivos presentes em jogos } \\
\text { conhecidos dos jovens }\end{array}$ \\
\hline $\begin{array}{l}\text { Coordenação } \\
\text { de gestos }\end{array}$ & $\begin{array}{l}\text { No coletivo, inicialmente podem } \\
\text { procurar estabelecer vínculos. } \\
\text { contato visual, o mesmo para expressão } \\
\text { facial e expressão de emoções. } \\
\text { Modos de comunicar podem } \\
\text { acontecer sem a fala. Repetição de ações, } \\
\text { palavras (quando já iniciam a falar) e na } \\
\text { escolha de objetos. } \\
\text { Podem abrir e fechar os jogos } \\
\text { inicialmente, sem explorar. A alegria pode } \\
\text { vir na forma de bater com as pontas dos } \\
\text { dedos no alto da cabeça, como a comemorar } \\
\text { o que fazem, ou ainda no olhar } \\
\text { alegre/sorridente, ou ainda com sons, são } \\
\text { modos de linguajar. } \\
\text { O medo pode vir na forma de tapar os } \\
\text { ouvidos, chorar, afastar-se, esconder-se } \\
\text { embaixo das mesas. } \\
>\quad \text { Inquietações podem acontecer e, em } \\
\text { alguns casos, temos o sentar no chão, } \\
\text { repetição de gestos com um objeto, ficar a } \\
\text { correr pelo ambiente, esconder-se atrás da } \\
\text { porta. }\end{array}$ & $\begin{array}{l}>\text { Elementos contidos nos jogos: } \\
\text { interatividade. } \\
>\text { Situações nos jogos mobilizam a } \\
\text { atenção durante o jogar, como: sons, } \\
\text { imagens vídeos e animações. } \\
>\text { Condutas acontecem como o choro, } \\
\text { repetições de gestos com determinado } \\
\text { objeto. Observamos que em muitas } \\
\text { situações esta inquietude acontecia devido } \\
\text { o volume dos sons no jogo. Nesse caso, o } \\
\text { controle do volume, de acordo com cada } \\
\text { jovem, deve ser implementado. } \\
>\quad \text { Outras ações manifestando agitação e } \\
\text { inquietude aconteciam e podiam estar } \\
\text { relacionadas a circunstâncias presentes no } \\
\text { viver cotidiano. }\end{array}$ \\
\hline $\begin{array}{l}\text { Coordenação } \\
\text { de ideias }\end{array}$ & $\begin{array}{l}\text { Podem mostrar o interesse por objetos } \\
\text { específicos, vídeos, jogos e podem } \\
\text { permanecer neles durante longo período. } \\
\text { p O interesse se mostra através do pedido } \\
\text { para jogar, por vezes apontando para } \\
\text { aqueles dispositivos, puxando os oficineiros } \\
\text { pelas mãos para mostrar o que vem } \\
\text { experimentando, ou na forma de palavras, } \\
\text { pequenas frases. }\end{array}$ & $\begin{array}{l}\text { Elementos contidos nos jogos: } \\
\text { personagens conhecidos por eles. } \\
\text { São atraídos pela jogabilidade, o ato } \\
\text { de jogar com praticidade utilizando um } \\
\text { dispositivo como o tablet. }\end{array}$ \\
\hline $\begin{array}{l}\text { Coordenação } \\
\text { de Emoções }\end{array}$ & $\begin{array}{l}\text { Observamos um estranhamento na } \\
\text { interação com elementos que podem } \\
\text { provocar sustos, tensões, medos no } \\
\text { ambiente, assim como podem alegrar. } \\
\text { Observa-se em algumas situações o } \\
\text { receio, o temor e o medo. Estas emoções } \\
\text { têm relação com diferentes elementos para } \\
\text { cada jovem: sons, cores, imagens de } \\
\text { objetos, processos que se transformam no } \\
\text { transcurso da experiência. } \\
>\text { Observamos a vibração e alegria desde } \\
\text { o encontro com um fazer que parece }\end{array}$ & $\begin{array}{l}\text { O momento inicial dos jogos que foram } \\
\text { inseridos nas oficinas pode de certa forma } \\
\text { causar um estranhamento. Mas depois do } \\
\text { primeiro contato, observamos interesse e } \\
\text { envolvimento com jogos. } \\
\text { As emoções de receio, temor, medo, } \\
\text { quando causadas por dispositivos dos } \\
\text { jogos, podem ser auxiliadas com a função } \\
\text { em que o próprio jogador passa a controlar } \\
\text { a iluminação da imagem, o volume do } \\
\text { som, ou ainda a contar com o apoio afetivo } \\
\text { do oficineiro jogador durante o jogar. }\end{array}$ \\
\hline
\end{tabular}




\begin{tabular}{|c|c|c|}
\hline & $\begin{array}{l}\text { possível, a fase de um jogo, o simples iniciar } \\
\text { a jogar, mas estas emoções podem se } \\
\text { alterar na relação com as circunstâncias do } \\
\text { ambiente e do sujeito. }\end{array}$ & \\
\hline \multicolumn{2}{|c|}{$\begin{array}{l}\text { Transformações nas coordenações de ações } \\
\text { Coordenações de ações novas e emergentes }\end{array}$} & $\begin{array}{l}\text { Dispositivos a estarem presentes na } \\
\text { Plataforma de J ogos Digitais }\end{array}$ \\
\hline $\begin{array}{l}\text { Coordenação } \\
\text { de Gestos }\end{array}$ & $\begin{array}{l}\text { Atenção pode estar endereçada a } \\
\text { imagens e a movimentos presentes nos } \\
\text { jogos. } \\
\text { quando engloram diferentes jogos no ambiente, } \\
\text { quados nas oficinas de jogos. } \\
>\text { Podem sair das cadeiras e lançar o olhar } \\
\text { para o que os outros fazem. } \\
>\text { Temos a ampliação das ações em que } \\
\text { passam a experimentar o jogar com o outro. }\end{array}$ & $\begin{array}{l}>\text { Elementos da plataforma, Animação do } \\
\text { jogo. } \\
>\text { Variedade de jogos em um único } \\
\text { ambiente. } \\
>\text { Interatividade de forma adaptativa. } \\
>\text { Várias fases no jogo aumentando os } \\
\text { desafios e possibilidades de exploração de } \\
\text { cenários, situações. }\end{array}$ \\
\hline $\begin{array}{l}\text { Coordenação } \\
\text { de Ideias }\end{array}$ & $\begin{array}{l}\text { Podem estabelecer novos modos de } \\
\text { comunicação, através da escrita ou mesmo } \\
\text { através de gestos no ambiente. } \\
>\quad \text { Em algumas situações manifestam a } \\
\text { necessidade da presença do outro. } \\
>\text { São capazes de aceder, pouco a pouco a } \\
\text { fala e podem tornar fluentes este modo de } \\
\text { comunicação. } \\
>\text { Potencialidades lógicas estão em } \\
\text { destaque, por exemplo, no vencer fases de } \\
\text { jogos mais complexos, em alguns casos, de } \\
\text { modo brilhante. } \\
>\text { Temos aqui a multisensorialidade, pois } \\
\text { se ampliam os modos sensório-motores de } \\
\text { acoplamento com diferentes mídias no } \\
\text { ambiente de jogos digitais, o que favorece o } \\
\text { encontro com o outro. }\end{array}$ & $\begin{array}{l}\text { Variedade de estilos de jogos } \\
\text { (estratégia, multiplayer, jogos de } \\
\text { plataforma, casuais, etc.). } \\
>\text { Interatividade e Jogos multiplayer. } \\
>\text { Comunicação (fala, escrita, gestos) no } \\
\text { mesmo jogo. } \\
\text { Elementos para comemorar de forma } \\
\text { adaptativa. } \\
\text { Observação: Aprendemos com crianças } \\
\text { autistas que elas podem vibrar quando } \\
\text { perdem, o que pode estar associado a } \\
\text { outros elementos que não pontuações, } \\
\text { como luzes que aparecem e são lançadas, } \\
\text { ou outros dispositivos que surgem no final } \\
\text { das fases de um jogo. } \\
>\text { Diferentes mídias áudio, vídeo, imagem } \\
\text { e animações, favorecendo a interatividade. }\end{array}$ \\
\hline $\begin{array}{l}\text { Coordenação } \\
\text { de Emoções }\end{array}$ & $\begin{array}{l}\text { Alguns jovens experimentam fruição } \\
\text { estética no jogar. Temos uma maleabilidade } \\
\text { e fluidez que se mostram como processos } \\
\text { que produzem prazer. } \\
>\text { Interação pode mostrar-se serena com } \\
\text { diferentes mídias, sons, imagens e escritas } \\
\text { no ambiente, a partir da descoberta de que } \\
\text { podem modelar estes usos nos jogos } \\
\text { digitais: aumentar e baixar sons, ampliar ou } \\
\text { reduzir a tela, entre outras ações. } \\
>\quad \text { Circunstâncias de sofrimento podem } \\
\text { emergir e interagem com problemáticas que } \\
\text { dizem respeito a cada jovem no percurso do } \\
\text { viver. }\end{array}$ & $\begin{array}{l}\text { Gráfico, design, áudio e vídeo, unidos } \\
\text { durante o jogo de forma atrativa. } \\
>\text { Adaptabilidade nos controles de } \\
\text { dificuldade, som, imagem, vídeo e diversos } \\
\text { outros elementos do jogo. }\end{array}$ \\
\hline
\end{tabular}

Fonte: elaborada pelos autores.

A metodologia que utilizamos para o desenvolvimento da pesquisa compreende a produção de diários de bordo em que os oficineiros acompanham as ações dos jovens no ambiente.

A tabela acima foi organizada levando em conta as ações recorrentes que pudemos identificar com o propósito de construir as informações necessárias para o desenvolvimento da plataforma. Os resultados dessa tabela se colocam como uma base para entender e elencar quais elementos dos jogos são atrativos para os jovens inseridos no CAPSi que participam das oficinas. E então, damos continuidade ao desenvolvimento e nossa reflexão se situa nesta 
relação entre modos de coordenar condutas dos jovens, os estudos que realizamos sobre o autismo e sobre os dispositivos capazes de potencializar processos cognitivos e afetivos de jovens em situações de jogo.

\subsection{A construção da plataforma}

Segundo Andrade et al. (2004), os jogos podem ser desenvolvidos a partir de objetivos psicopedagógicos consolidados e serem utilizados na relação com extensa gama de processos cognitivos, como também, a partir de sistemas inteligentes adaptativos que forneçam recursos adaptáveis às necessidades de cada jogador.

A proposta de uma plataforma contendo jogos com funções adaptativas surge a partir da necessidade de desenvolver ferramentas que tomam como base as singularidades, interesses e problemáticas de jovens em situações e circunstancias de transtorno no desenvolvimento.

Conforme já referimos, a construção da plataforma ocorre em jogos multiplataforma utilizando a Unity, e, dentro das linguagens as quais ela dá suporte, utilizamos as linguagens C\# e JavaScript.

A plataforma propõe a utilização de jogos em uma linguagem simples e com uma interface que convida os jovens a pousarem a atenção e se engajarem em situações de jogo, ao mesmo tempo, permite aos profissionais e/ou oficineiros observarem e acompanharem as ações que coordenam no ambiente.

Entre as técnicas de adaptabilidade existentes, tem sido utilizada a técnica de Balanceamento Dinâmico de Dificuldade, que, de acordo com Siebel (2011), em jogos acontece de forma automática, ou seja, os parâmetros, cenários e comportamentos de um jogo são alterados em tempo real e isso acontece de acordo com as habilidades do jogador.

Aplicamos a técnica de balanceamento de dificuldade para que os jogos atuem com a adaptação dos elementos neles contidos. Um exemplo na experiência das oficinas foi quando um jogador em circunstância de autismo estava jogando e uma característica que o mobilizou para o jogo foi o som. O elemento som pode afastar ou engajar jovens autistas na experiência das oficinas de jogos, portanto, à medida que o jogador avança ou não nas fases, o elemento som é habilitado ou desabilitado, promovendo a adaptabilidade na relação com as ações dos jogadores.

Tendo por base os elementos contidos na Tabela 1, sobre as coordenações de ações observadas e analisadas no transcurso da experiência do Programa Rede de Oficinandos na Saúde, catalogamos alguns elementos que são mais atrativos para eles. Os jogos vão sendo adaptados de acordo com as ações dos jogadores e a adaptação durante o jogo atua alterando os elementos do jogo. Um exemplo acontece no jogo "Estellar", no qual a cada vitória ou derrota, os elementos como som, velocidade da aeronave e cor do plano de fundo vão sendo modificados.

A Figura 1 apresenta alguns jogos que estão inseridos na plataforma, os mesmos estão sendo finalizados para adicionar técnicas adaptativas. 
Figura 1 - Jogos em desenvolvimento contidos na plataforma.
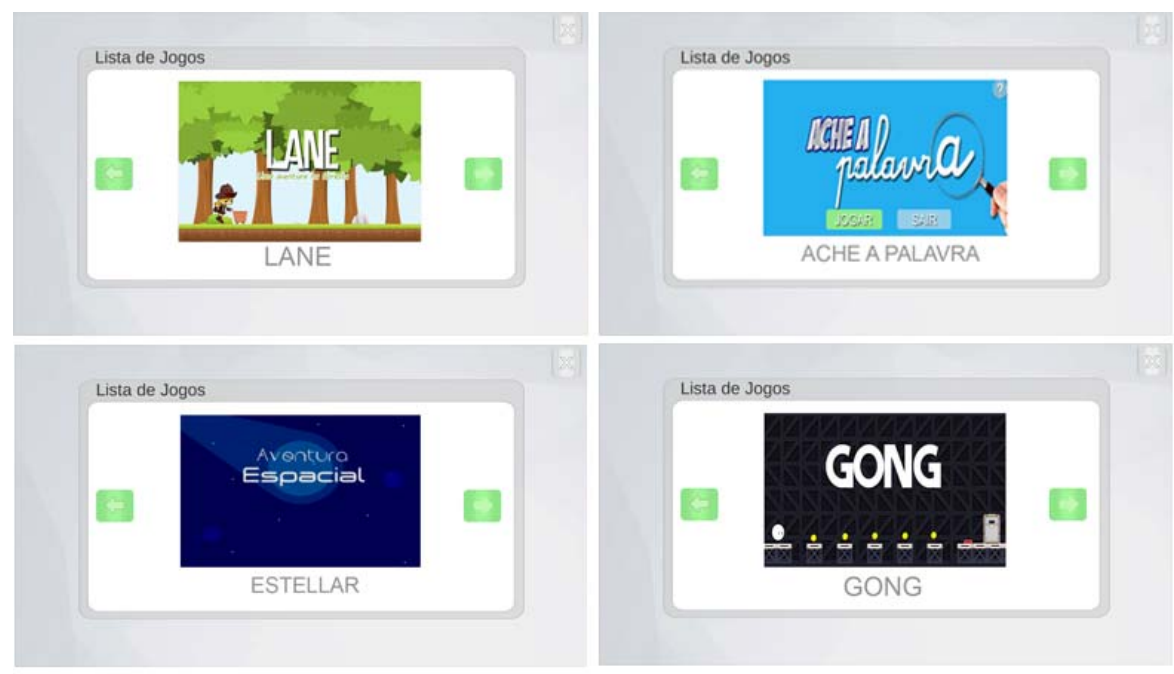

Fonte: elaborada pelos autores.

Planejamos realizar a validação com os jovens inseridos no CAPSi na utilização da plataforma com a participação da equipe de profissionais que atuam na instituição e integram o Programa Rede de Oficinandos na Saúde. Através de oficinas e testes com a plataforma, serão acompanhadas as interações que acontecem no modo de coordenar condutas na experiência dos jovens com a plataforma. Neste momento da pesquisa, tomaremos novamente os diários de bordo para produzir entendimentos sobre como a plataforma de jogos faz disparar processos afetivos e cognitivos na experiência dos jovens autistas, assim como junto aos demais jovens nas oficinas, pois consideramos também os processos vividos pelos jovens que apresentam deficiência mental e/ou depressão.

\section{Considerações Finais}

A pesquisa que realizamos acontece a partir de um trabalho semanal de oficinas de jogos digitais em um CAPSi de Mossoró. Para a equipe de pesquisa esta experiência é essencial porque permite a produção de saberes, entendimentos sobre como operam os sujeitos em circunstâncias de transtorno de desenvolvimento. Priorizamos o trabalho sobre os diários de bordo de estudantes e pesquisadores. Nas oficinas sempre temos dois colegas responsáveis, então vamos alternando as situações em que um joga com os jovens e o outro se dedica no ato de escrever. Temos um conjunto de redes de escritas, estas se referem a cada jovem e ao coletivo, pois cada grupo das oficinas é composto por oito jovens.

A proposta para a escrita do artigo fez com que organizássemos a tabela em que as ações recorrentes foram destacadas, mas pousamos também a nossa atenção para as ações que se diferenciam, pedidos de ajuda na manifestação do sofrimento, momentos de alegria e festa, enfim, o que compõe a experiência, os processos do viver-conhecer. 
Como ações da pesquisa que segue seu curso de desenvolvimento, temos a finalização da plataforma, de forma que atue com a recomendação durante a aplicação no ambiente; a validação junto aos jovens do CAPSi e a expansão da plataforma para outros dispositivos, além da inclusão de outras técnicas adaptativas em pesquisa.

O trabalho traz junto da operacionalização a alegria e potência no encontro entre pesquisadores das ciências humanas e da ciência da computação com estudantes de mestrado e de graduação destas duas grandes áreas. Quando nossa atenção está dirigida a inventar novas formas de cuidar e aprender nos ambientes onde estamos, estes encontros tornam-se motivo de alegria na experiência universitária e fortalecem, em nosso entendimento, o sentido de estarmos na universidade pública, a inventar dispositivos necessários para o trabalho em saúde mental e em educação.

\section{Referências}

ANDRADE, G. et al. Extending reinforcement learning to provide dynamic game balancing. En Proceedings of the Workshop on Reasoning, Representation, and Learning in Computer Games, 19th International J oint Conference on Artificial Intelligence (IJCAI), 2005.

ANDRADE, L. C. et al. Mapa do Zoológico - Captura Cognitiva para Disfunção Executiva. XV SBIE - Simpósio Brasileiro de informática na Educação, Manaus, 2004.

CRAWFORD, Chris. The art of computer game design. Washington State University Vancouver, 1984. $81 \mathrm{p}$.

KOSTER, R. Theory of fun for game design. O'Reilly Media, Inc., 2010.

MATURANA, H; VARELA, F. A árvore do conhecimento: as bases biológicas da compreensão humana. São Paulo: Editora Palas Athena, 2001.

MONTE, W. S. do. Oficinando com jovens: análise de processos de atenção na experiência com jogos digitais. Dissertação (Mestrado em Ambiente, Tecnologia e Sociedade) Universidade Federal Rural do Semi-Árido. Mossoró/RN, 2014.

SILVA, A. S. Desvelando o sentido da deficiência mental: uma leitura psicanalítica. Mental, Barbacena, v.3, n.4, jun. $2005 . \quad$ Disponível em: <http://pepsic.bvsalud.org/scielo.php?script=sci_arttext\&pid=S1679$44272005000100009 \&$ lng=pt\&nrm=iso>. Acesso em 27 dez. 2015.

SILVA, M. P. Inteligência Artificial Adaptativa para Ajuste Dinâmico de Dificuldade em Jogos Digitais. Dissertação (Mestrado) -- Universidade Federal de Minas Gerais, 2015.

SIMONDON, G. Du mode d'existence des objets techniques. Paris: Aubier, 1958; 1989. Millon, 2009.

L'individuation à la lumière des notions de forme et d'information. Grenoble: Jérôme VARELA, F. Conhecer: as ciências cognitivas tendências e perspectivas. Lisboa: Instituto Piaget, 1988. 
VARELA, F.; J. THOMPSON, E. T.; ROSCH, E. A mente corpórea: ciência cognitiva e experiência humana. Lisboa: Instituto Piaget 1991.

VON FOERSTER, H. Las semillas de la cibernética. Barcelona: GEDISA, 1996.

WATZLAWICK, P; KRIEG, P (Orgs). El ojo del observador: contribuciones al constructivismo. Barcelona: Gedisa, 2009.

Recebido em setembro de 2016

Aprovado para publicação em agosto de 2017

\section{Francisco Milton Mendes Neto}

Programa de Pós-Graduação em Ciência da Computação, Programa de Pós-Graduação em Cognição,

Tecnologias e Instituições e Programa de Pós-Graduação em Ensino - Universidade Federal Rural do Semi-

Árido - UFERSA, Brasil, miltonmendes@ufersa.edu.br

\section{Karla Rosane do Amaral Demoly}

Programa de Pós-Graduação em Cognição, Tecnologias e Instituições - Universidade Federal Rural do Semi-Árido - UFERSA, Brasil, karla.demoly@ufersa.edu.br

\section{Everton Jales de Oliveira}

Graduação em Ciência da Computação - Universidade Federal Rural do Semi-Árido - UFERSA, Brasil, verto.jales@gmail.com

\section{Mariza Souza Moura}

Programa de Pós-Graduação em Ciência da Computação - Universidade Federal Rural do Semi-Árido UFERSA, Brasil, marizasouzamoura@gmail.com

\section{Rafael de Almeida Rodrigues}

Programa de Pós-Graduação em Ciência da Computação - Universidade Federal Rural do Semi-Árido UFERSA, Brasil, rafael_allx@hotmail.com

\section{Ramiro de Vasconcelos dos Santos J unior}

Programa de Pós-Graduação em Cognição, Tecnologias e Instituições - Universidade Federal Rural do Semi-Árido - UFERSA, Brasil, ramirovsjunior@gmail.com 